ScIDice

\section{Comparison between the Efficiency of Alo evera Extract and Alvogyl in Dry Socket (Alveolar Osteitis) Management}

Research Article

Ali Hatem Ali ${ }^{1}$, Zafin Karabeit ${ }^{2}$, Salma Al Nesser ${ }^{3 *}$

${ }^{1}$ Oral and Maxillofacial Department, Dentistry College, Damascus University, Damascus, Syria.

${ }^{2}$ Assistant Professor, Oral and Maxillofacial Department, Dentistry College, Damascus University, Damascus, Syria.

${ }^{3}$ Department of Pediatric Dentistry, Faculty of Dentistry, Damascus University, Syria.

\title{
Abstract
}

Background: Dry socket is the most common complication following tooth extraction. However, it is a painful and annoying condition for the patient, and up to the present time the causes of this condition have not been precisely determined, and the proposed treatments aim to relieve symptoms, until the socket heals itself.

Aim: The main objective of this study is to compare the efficacy of Alo evera extract and Alvogyl in pain relief associated with dry socket.

Materials and Methods: 40 patients (ranged from 29 to 60 years), who had dry socket after tooth extraction in the molar region, were included in the study. They were divided equally and randomly into two groups: group A (Aloe vera) and group B (Alvogyl). Pain values were recorded in the two groups after 2, and 7 days.

Results: After 2, and 7 days Aloe vera showed a statistically significant difference in relieving pain compared to Alvogyl ( $\mathrm{p}$ value $<0.05)$.

Conclusion: The use of Aloevera extract shows promising results in terms of pain relief in patients with dry socket.

Keywords: Dry Socket; Aloevera Extract; Alvogyl.

\section{Introduction}

Dry socket is the most common post-extraction complication [1]. This term first appeared in the literature in 1896 by Crawford [2], since that many terms have appeared to refer to this complication as: alveolar osteitis (AO), localized osteitis, postoperative alveolitis, alveolalgia, alveolitis sicca dolorosa, septic socket, necrotic socket, localized osteomyelitis, and fibrinolytic alveolitis. However, the term dry socket is still the most common term [3]. In 2002 Blum suggested a definition that can be used universally as a standard definition of dry socket: "postoperative pain in and around the extraction site, which increases in severity at any time between 1 and 3 days after the extraction accompanied by a partially or totally disintegrated blood clot within the alveolar socket with or without halitosis" [3]. Studies with large sample sizes indicate that the incidence of dry socket after routine tooth extraction is recorded at rates less than 5\% [4]. Blum stated that well-controlled studies have reported the incidence as $25-30 \%$ after the removal of impacted mandibular third molars [3].The etiology of dry socket is not precisely defined [5]. However, Birn suggested that dry socket develops because of high fibrinolytic activity in and around the socket, which can leadto dissolution of the blood clot [6]. The increase in locally fibrinolysis isa result of an increase in the pathways of converting plasminogen to plasmin [7], which is stimulated by an elevated release of tissue activators released from the alveolar bone infected or traumatized [8]. The tissue activators release two types of enzymes, bradykinins and kininogenases, which play a vital role in generating the perception of pain [7]. Dry socket starts between the first and the third day after tooth extraction and $95 \%$ to $100 \%$ of cases occur within a week of extraction $[9,10]$. Studies published in the literature indicate Several contributing factors to be associated with increased risk of dry socket, including: traumatic extraction [11], taking oral contraceptives, bad oral hygiene [12], patient sex [13], smoking [14], age [15], extraction Site, and previous experience of dry socket [3]. Management strategies for dry socket work to relieve patient's pain, and protect the site until healing occurs spontane-

*Corresponding Author

Salma Al Nesser MSc, DDS,

Department of Pediatric Dentistry, Faculty of Dentistry, Damascus University, Syria.

E-mail: salma.alnesser93@gmail.com

Received: January 11, 2021

Accepted: January 29, 2021

Published: February 12, 2021

Citation: Ali Hatem Ali, Zafin Karabeit, Salma Al Nesser. Comparison between the Efficiency of Aloevera Extract and Alvogyl in Dry Socket (Alveolar Osteitis) Management. Int J Dentistry Oral Sci. 2021;8(2):1578-1582. doi: http://dx.doi.org/10.19070/2377-8075-21000313

Copyright: Salma Al Nesser ${ }^{\circ}$ 2021. This is an open-access article distributed under the terms of the Creative Commons Attribution License, which permits unrestricted use, distribution and reproduction in any medium, provided the original author and source are credited. 
ously. Alvogyl dressing is commonly used for management of dry socket, which contains eugenol (analgesic and anti-inflammatory), iodoform (antimicrobial), and butamen (anesthetic) [16].

Aloe vera (Aloe barbadensis) is one of the most popular plants nowadays and it is receiving remarkable scientific interest. The history of this plant's use goes back to the Babylonian era. Aloe vera grows in warm areas and cannot survive in freezing temperatures [17]. There are about 75 active chemical compounds in Aloe vera, including vitamins $\mathrm{A}, \mathrm{B}$ and $\mathrm{C}$, which have a positive effect on the immune system, as well as vitamin $\mathrm{C}$ has a role in wound healing, enzymes (such as Carboxy-peptidase, which helps reduce inflammation), sugars (including gluco-mannans., which accelerate the healing process of wounds), sterols: these compounds have an anti-inflammatory role (such as Lupeol, which has an antiseptic and analgesic role) [18], and anthraquinones which when present in small amount are considered strong analgesics [19]. Aloe vera has been used in many aspects within dentistry, including, oral lichen planus, periodontitis, dry socket, and root canals filling material in primary teeth [18].

\section{Materials and Methods}

A randomized controlled clinical trial was conducted at the department of oral and maxillofacial surgery/Faculty of Dentistry/ Damascus University. Before starting the procedure, approval was taken from the Research and Ethics Committee.

Sample size was calculated based on $G$ power. 40 patients ( $25 \mathrm{fe}-$ males and 15 males ranged between 29 to 60 years) established dry socket after maxillary or mandibular molar extraction (36 cases in mandibular molar region, 4 casesin maxilla molar region), who have not received any treatment. Patients free from any systemic diseases and without any signs of active infection in extracted sockets were included in the study. Exclusion criteria: were Pregnant and lactating women, or patients on oral contraceptives, previous history of antibiotic and anti-inflammatory therapy for the treatment of dry socket, participants without any underlying systemic disease or compromised immunity, smokers, and patients, who did not commit to attend follow-up and monitoring sessions.

The patients were divided equally and randomly into two groups using flipping a coin.

Group A (study group): Included 20 patients (7 males and 13 females). Aloe vera extract was applied to the dry infected socket.

Group B (control group): Included 20 patients (8 males and 12 females). Alvogyl was applied into the socket infected with dry socket.

\section{Method of preparation of Aloe Vera extract}

Aloe Vera extract was obtained by working in the postgraduate laboratory/department of Pharmacognosy/Faculty of Pharmacy/Damascus University. The fresh Aloe vera leaves were collected from the plant, washed in the running tap water for 15 minutes then rinsed with sterile distilled water [20], disinfected with $70 \%$ ethanol alcohol [21], cut with a sterile knife, and then dried well (several days) outdoors. The dried plant cuttings were then crushed into small pieces. The weight of these pieces that would be subjected to the extraction process was recorded [22]. A standardized weight of 20.06 grams was obtained for all pieces. The plant extracts were prepared by using soxhlet apparatus using distilled water as a solvent for several hours [22].

The extraction was done by maceration method, where 20.06 grams of the plant were placed in a Laboratory flask and $200 \mathrm{ml}$ of distilled water were added to it. The extraction process lasted for two days. After the completion of the extraction process, the liquid extract was collected and dried using a rotary evaporator device until it was completely dry, then the extracted sample was weighed to 8.3 grams.

The extraction yield was determined according to the following method:

$$
\begin{aligned}
& x=\text { extraction yield } \\
& x=(\text { we ightof s a m le af terextraction } / \\
& \text { weightof samplebeforeextraction }) \times 100 \\
& x=(8.3 / 20.06) \times 100 \\
& x=41.37 \%
\end{aligned}
$$

The extract was then collected and stored in a sterile, opaque glass container at room temperature and closed well until use.

\section{Alvogyl dressing}

Alveopaste Pengha Iodoform Paste (Manufacturer- Produits Dentaires Switzerland) was used. Each jar (15grams) contains: Penghawar -Djambi 4\% (hemostatic), Iodoform 16\% (antiseptic), Ethyl Aminobenzoate 26\% (local anesthetic), Eugenol 14\%, Oil of Mint $8 \%$, and excipient ad $100 \%$.

\section{Treatment Protocol}

After taking the medical history of the patient and the agreements to the conditions of the study with the written consent, the group in which the patient will enter is chosen by flipping a coin.

A gentle irrigation of the socket was performed with a warm saline then a small cotton swab was passed over the socket walls to remove food debris, and remnants of the disintegrated clot, taking care not to curettage the socket walls. Irrigation was repeated again, then the aforementioned commercial Alvogyl dressing was placed intra-socket and a piece of sterile gauze is placed over the socket. Patient was asked to follow-up after 48 hours. After that, the socket was re-irrigated with saline. A clean dressing was put back in. The patient was asked to follow-up after 48 hours, assess the patient's condition and apply a new dressing when needed. The patient was asked to follow-up after two days to evaluate his condition in the control group.

In the study group, several drops of sterile distilled water wasadded to the Aloe vera extract, to be placed intra-socket instead of Alvogyl dressing. A piece of sterile gauze was placed over the extract and applied intra-socket.

Patients' pain values were recorded 2 , and 7 days after the start of treatment in both groups using a visual analog scale (VAS), which is based on the patient's personal experience and consists of a ruler of $10 \mathrm{~cm}$ in length printed on its left end (no pain) and printed on the right end. (worst pain) and the patient was asked to 
point the location on the ruler representing severity of his pain.

(Figure 1)

\section{Statistical Analysis}

Normality of distribution was checked with KolmogorovSmirnov test. Data showed normal distribution.

Data were analyzed using SPSS V.23 (IBM; CORP., ARMONK, USA). The level of the P value was set $5 \%$, and the level of confidence was set at $95 \%$.

\section{Results}

Descriptive results for intergroup: The mean VAS scores at baseline in group A and group B were $7.70 \pm 0.73$ and $7.60 \pm 0.88$ respectively. After 2 days, results were $2.50 \pm 0.95$ and $3.80 \pm 0.83$ respectively. Moreover, after 7 days scores were $0.20 \pm 0.41$ and $0.70 \pm 0.92$ respectively.

Intergroup comparison: The unpaired t-test was used to compare the mean VAS scores between the two groups.Results showed that pain score after 2 , and 7 days were significantly better in Aloe
Vera group compared to Alvogyl group $(\mathrm{p}<0.05)$. (Table 1)

Intragroup comparison: The unpaired t-test was used to comparethe mean VAS scores. The observed resultsshowed a significantly reduction in mean scores of VAS when comparing between two periods (After 2 days- Baseline), (After 7 days- Baseline), and (After 7 days- After 2 days) in both groups ( $<<0.00$ (Table 2$)$.

\section{Discussion}

Dry socket is a self-limiting condition. Although it is extremely debilitating and painful [23], dentists often underestimate the severity of the pain experienced by patients, and these patients are not given adequate attention and care [24].

This study found that both Aloe vera extract and Alvogyl had an effect in relieving pain after (2 and 7) days in patients with dry socket. Supe et al. found that the mean VAS scores in Alvogyltreated group were 3.96 and 0.44 on the third and seventh day, respectively after application of the treatment. Their study concluded that Alvogyl had a faster effect on pain relief than Zinc oxide eugenol in patients with dry socket [25]. Lenka et al. found that the mean VAS scores were 2.90 and 4.10 in the Alvogyl-treat-

Figure 1. Visual analog Scale.

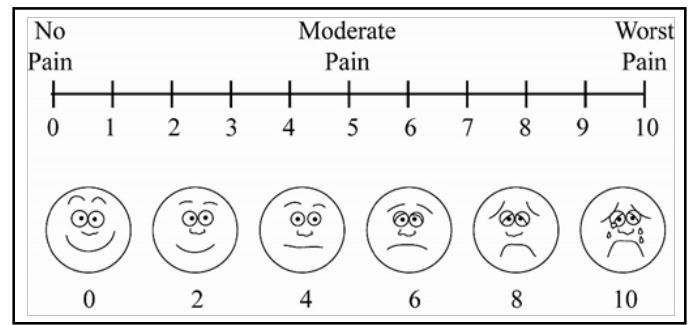

Table 1. Comparison of visual analogue pain scale between group A, and B.

\begin{tabular}{|c|c|c|c|c|c|c|c|}
\hline \multirow{7}{*}{$\begin{array}{l}\text { Intergroup } \\
\text { comparison }\end{array}$} & VAS & Groups & Mean & Std. Deviation & t-test value* & P-value & Mean Difference \\
\hline & \multirow{2}{*}{ Baseline } & Group A & 7.70 & 0.73 & \multirow{2}{*}{0.39} & \multirow{2}{*}{0.699} & \multirow{2}{*}{0.10} \\
\hline & & Group B & 7.60 & 0.88 & & & \\
\hline & \multirow{2}{*}{$\begin{array}{l}\text { After } 2 \\
\text { days }\end{array}$} & Group A & 2.50 & 0.95 & \multirow{2}{*}{-4.611} & \multirow{2}{*}{$0.000^{* *}$} & \multirow{2}{*}{-1.30} \\
\hline & & Group B & 3.80 & 0.83 & & & \\
\hline & \multirow{2}{*}{$\begin{array}{l}\text { After } 7 \\
\text { days }\end{array}$} & Group A & 0.20 & 0.41 & \multirow{2}{*}{-2.213} & \multirow{2}{*}{$0.033^{* *}$} & \multirow{2}{*}{-0.50} \\
\hline & & Group B & 0.70 & 0.92 & & & \\
\hline
\end{tabular}

$*$ Unpaired t-test, ${ }^{* *}$ significant difference $(\mathrm{p}$-value $<0.05)$.

Table 2. Comparison of visual analogue pain scale between two periods Intragroup.

\begin{tabular}{|c|c|c|c|c|c|}
\hline \multirow{7}{*}{$\begin{array}{l}\text { Intragroup } \\
\text { comparison }\end{array}$} & Groups & $\begin{array}{c}\text { Compare VAS between } \\
\text { the two periods: }\end{array}$ & $\begin{array}{c}\text { t-test } \\
\text { value* }\end{array}$ & P-value & Mean Difference \\
\hline & \multirow{3}{*}{ Group A } & After 2 days- Baseline & -27.9 & $0.000 * *$ & -5.2 \\
\hline & & After 7 days- Baseline & -48.734 & $0.000 * *$ & -7.5 \\
\hline & & After 7 days- After 2 days & -15.657 & $0.000 * *$ & -2.3 \\
\hline & \multirow{3}{*}{ Group B } & After 2 days- Baseline & -20.389 & $0.000 * *$ & -3.8 \\
\hline & & After 7 days- Baseline & -36.208 & $0.000^{* *}$ & -6.9 \\
\hline & & After 7 days- After 2 days & -19.304 & $0.000^{* *}$ & -3.1 \\
\hline
\end{tabular}

$*$ Unpaired t-test, ${ }^{* *}$ significant difference $(\mathrm{p}$-value $<0.00)$. 
ed group, and Zinc oxide eugenol-treated group, respectively, and they concluded that Alvogyl significantly better in relieving pain than Zinc oxide eugenol dressing [26]. Faizel et al carried out a study that concluded that initial onset of analgesia was quicker with Alvogyl than Neocone and Zinc oxide eugenol, but Neocone was able to provide early and lasting pain relief. Further, fewer change of dressings was required with Neocone as compared to the other two [27]. Alvogyl contains eugenol, which can also inhibit the inflammatory process and provide analgesic effects by inhibiting the action of prostaglandins [28]. The result of this study showed that the pain score was significant lower in Aloe vera extract-treated group compared to Alvogyl-treated group 2 and 7 days from the baseline ( $p$-value $<0.05$ ). Nimma et al. published a study about the effectiveness of aloe vera in healing the socket after extraction, it included two groups (20 patients in each group), the authors prescribed only analgesics in the first group, and in the second group patients were given Aloe vera soaked gel foams (almost $500 \mathrm{mg}$ capsule of Aloe vera powder was mixed with $2 \mathrm{ml}$ of saline and then it was soaked with gelatin foam placed in the socket), the authors concluded that there were statistical differences in the group treated with Aloe vera in analgesia following a tooth extraction on the third and seventh day [29]. Kaya et al. found that Salicept Patches can be used as an alternative to Alvogyl in the management of dry socket, as the authors found no statistical differences in pain relief between the Alvogyl -treated group and the Salicept Patches-treated group [28]. The Salicept Patch is a freeze-dried pledget that contains Acemannan Hydrogel (Carrington Laboratories) obtained from the clear inner gel of Aloe vera L. [30]. Acemannan inhibits the inflammatory process and relieves pain by interfering with the arachidonic acid pathway by way of cyclooxygenase [28].

The current study used the extract of whole Aloe Vera leaf to take advantage of the effects of compounds believed to contribute to pain relief, including:1- Carboxy-peptidase which inactivates bradykinins and produces an anti-inflammatory effect. During the inflammatory process, bradykinin produces pain associated with vasodilation and, therefore, its hydrolysis produces an analgesic effect. 2-Anthraquinones in small amounts these compounds possess powerful analgesic [19]. 3-Lupeol which acts as an antiseptic and analgesic agent [18]. 4- Phenylalanine, this amino acid has anti-inflammatory effects by reducing vasodilation, therefore, reducing pain. 5- Salicylic acid, which works to prevent prostaglandin biosynthesis from arachidonic acid, which also reduces vasodilation and thus relieves pain [29]. In addition to Acemannan, whose mechanism in pain relief action was aforementioned.

\section{Conclusion}

Since pain is the main symptom of dry socket and the main reason for patients to visit the dentist, the current study focused on pain management associated with dry socket.

This study found that Aloe vera extract and Alvogyl were both effective in relieving pain in patients with dry socket. Aloe vera extract is superior to Alvogyl in its capacity to decrease pain level. Further investigations should be conducted to Aloe vera capacity in accelerate granulation tissue and healing epithelium formation in the dry socket, and its relationship with the patients' pain values.

\section{References}

[1]. Bowe DC, Rogers S, Stassen LF. The management of dry socket/alveolar osteitis. J Ir Dent Assoc. 2011 Dec-2012 Jan; 57(6): 305-10. PMID: 22338284.

[2]. Crawford JY. Dry socket. Dental Cosmos. 1896; 38: 929-31.

[3]. Blum IR. Contemporary views on dry socket (alveolar osteitis): a clinical appraisal of standardization, aetiopathogenesis and management: a critical review. Int J Oral Maxillofac Surg. 2002 Jun; 31(3): 309-17. PMID: 12190139.

[4]. Chow O, Wang R, Ku D, Huang W. Alveolar Osteitis: A Review of Current Concepts. J Oral Maxillofac Surg. 2020 Aug; 78(8): 1288-1296. PMID: 32348729.

[5]. Nusair YM, Younis MH. Prevalence, clinical picture, and risk factors of dry socket in a Jordanian dental teaching center. J Contemp Dent Pract. 2007 Mar 1; 8(3): 53-63. PMID: 17351682.

[6]. Birn H. Etiology and pathogenesis of fibrinolytic alveolitis ("dry socket"). International journal of oral surgery. 1973 Jan 1; 2(5): 211-63.

[7]. Almutairi BM. Dry sockets-a systemic review. Advancements in Life Sciences. 2019 Nov 27; 7(1): 48-57.

[8]. Kolokythas A, Olech E, Miloro M. Alveolar osteitis: a comprehensive review of concepts and controversies. Int J Dent. 2010; 2010: 249073. PMID: 20652078.

[9]. Gowda GG, Viswanath D, Kumar M, Umashanker D. Dry socket (alveolar osteitis): Incidence, pathogenesis, prevention and management. J Indian Acad Oral Med Radiol. 2013 Jul 1; 25(3): 196-9.

[10]. Pendharkar SS. Comprehensive review on alveolar osteitis. Int J Contemp Dent Med Rev. 2019; 2019: 010419.

[11]. Rakhshan V. Common risk factors of dry socket (alveolitis osteitis) following dental extraction: A brief narrative review. J Stomatol Oral Maxillofac Surg. 2018 Nov; 119(5): 407-411. PMID: 29723658.

[12]. Egauvoen I. Incidence of alveolar osteitis in two Johannesburg hospitals, South Africa. Johannesburg, South Africa: University of the Witwatersrand; 2016.

[13]. Mudali V, Mahomed O. Incidence and predisposing factors for dry socket following extraction of permanent teeth at a regional hospital in Kwa-Zulu Natal. South African Dental Journal. 2016 May; 71(4): 166-9.

[14]. Singh G, Aggarwal A, Singh P. RISK FACTORS FOR DRY SOCKET FOLLOWING EXTRACTION OF PERMANENT TEETH: A CLINICAL STUDY. Journal of Advanced Medical and Dental Sciences Research. 2016 Nov; 4(6).

[15]. Chuang SK, Perrott DH, Susarla SM, Dodson TB. Age as a risk factor for third molar surgery complications. J Oral Maxillofac Surg. 2007 Sep; 65(9): 1685-92. PMID: 17719384.

[16]. Eshghpour M, Ahrari F, Najjarkar NT, Khajavi MA. Comparison of the effect of low level laser therapy with alvogyl on the management of alveolar osteitis. Med Oral Patol Oral Cir Bucal. 2015 May 1; 20(3): e386-92. PMID: 25662557.

[17]. Sajjad A, Subhani Sajjad S. Aloe vera: An ancient herb for modern dentistry - A literature review. Journal of Dental Surgery. 2014; 2014.

[18]. Mangaiyarkarasi SP, Manigandan T, Elumalai M, Cholan PK, Kaur RP. Benefits of Aloe vera in dentistry. J Pharm Bioallied Sci. 2015 Apr;7(Suppl 1): S255-9. PMID: 26015726.

[19]. Joseph B, Raj SJ. Pharmacognostic and phytochemical properties of Aloe vera linn an overview. Int J Pharm Sci Rev Res. 2010 Jan 1; 4(2): 106.

[20]. Shende V, Telrandhe R. Formulation and evaluation of Tooth Gel from Aloe vera leaves extract. International Journal of Pharmaceutics and Drug Analysis. 2017 Oct 12: 394-8.

[21]. Badakhsh S, Eskandarian T, Esmaeilpour T. The use of aloe vera extract as a novel storage media for the avulsed tooth. Iran J Med Sci. 2014 Jul; 39(4): 327-32. PMID: 25031484.

[22]. Arunkumar S, Muthuselvam M. Analysis of phytochemical constituents and antimicrobial activities of Aloe vera L. against clinical pathogens. World Journal of Agricultural Sciences. 2009; 5(5): 572-6.

[23]. Punia SC, Garg S, Yadav R. Clinical Aspects of Dry Socket. Rama Univ. J. Dent. Sci. 2016; 3: 21-6.

[24]. Kamal A, Salman B, Razak NHA, Samsudin ABR. A Comparative Clinical Study between Concentrated Growth Factor and Low-Level Laser Therapy in the Management of Dry Socket. Eur J Dent. 2020 Oct; 14(4): 613-620. PMID: 32777838.

[25]. Supe NB, Choudhary SH, Yamyar SM, Patil KS, Choudhary AK, Kadam VD. Efficacy of Alvogyl (Combination of Iodoform + Butylparaminobenzoate) and Zinc Oxide Eugenol for Dry Socket. Ann Maxillofac Surg. 2018 Jul-Dec; 8(2): 193-199. PMID: 30693231.

[26]. Lenka S, Rathor K, Varu R, Dalai RP. Comparison between Alvogyland Zinc Oxide Eugenol Packing for the Treatment of Dry Socket: A Clinical Study. 
Indian Journal of Public Health Research \& Development. 2019 Nov 1; $10(11)$.

[27]. Faizel S, Thomas S, Yuvaraj V, Prabhu S, Tripathi G. Comparision between neocone, alvogyl and zinc oxide eugenol packing for the treatment of dry socket: a double blind randomised control trial. J Maxillofac Oral Surg. 2015 Jun; 14(2): 312-20. PMID: 26028852.

[28]. Kaya GŞ, Yapici G, Savaş Z, Güngörmüş M. Comparison of alvogyl, SaliCept patch, and low-level laser therapy in the management of alveolar osteitis. J Oral Maxillofac Surg. 2011 Jun; 69(6): 1571-7. PMID: 21398006.
[29]. Nimma VL, Talla HV, Bairi JK, Gopaldas M, Bathula H, Vangdoth S. Holistic Healing Through Herbs: Effectiveness of Aloe Vera on Post Extraction Socket Healing. J Clin Diagn Res. 2017 Mar; 11(3): ZC83-ZC86. PMID: 28511517.

[30]. Poor MR, Hall JE, Poor AS. Reduction in the incidence of alveolar osteitis in patients treated with the SaliCept patch, containing Acemannan hydrogel. J Oral Maxillofac Surg. 2002 Apr; 60(4): 374-9. PMID: 11928091. 